\title{
Use of Ionic Liquids for Liquid-Phase Microextraction of Polycyclic Aromatic Hydrocarbons
}

\author{
J ing-fu Liu, ${ }^{\dagger}$ Gui-bin J iang, ${ }^{* \dagger}+$ Yu-guang Chi, ${ }^{\dagger}{ }^{\ddagger}$ Ya-qi Cai, ${ }^{\dagger}$ Qing-xiang Zhou, ${ }^{\dagger}$ and J ing-Tian $\mathrm{Hu}^{\ddagger}$ \\ Key Laboratory of Environmental Chemistry and Ecotoxicology, Research Center for Eco-Environmental Sciences, \\ Chinese Academy of Sciences, P.O. Box 2871, Beijing 100085, China, and Department of Chemistry, Shandong University, \\ Jinan 250100, China
}

This paper demonstrates, for the first time, that ionic liquids (IL) such as 1-octyl-3-methylimidazolium hexafluorophosphate $\left(\left[\mathrm{C}_{8} \mathrm{MIM}\right]\left[\mathrm{PF}_{6}\right]\right)$ are excellent extraction solvents in liquid-phase microextraction (LPME). The unique properties of nonvolatility and adequate viscosity allow IL to be conveniently adopted as extraction solvents in both direct-immersion and headspace LPME. Model compounds, polycyclic aromatic hydrocarbons (PAHs), are conveniently and rapidly enriched in a 3- $\mu \mathrm{L}$ drop of $\left[\mathrm{C}_{8} \mathrm{MIM}\right]\left[\mathrm{PF}_{6}\right]$ suspended on the tip of a microsyringe followed by liquid chromatographic determination. Compared to 1-octanol, a larger volume drop of [ $\mathrm{C}_{8} \mathrm{MIM}^{\mathrm{M}}\left[\mathrm{PF}_{6}\right]$ can be formed and survive for a longer extraction time; therefore, a much higher enrichment factor for PAHs can be reached. For low-volatility PAHs, direct-immersion LPME provides higher enrichment factors than that of headspace LPME. However, the enrichment factor obtained by headspace LPME was almost 3-fold of that by direct-immersion LPME in a 30-min extraction of the most volatile PAH, naphthalene. For 30-min directionimmersion LPME of EPA priority PAHs, the enrichment factor, correlation coefficient $\left(\mathbf{R}^{2}\right)$, and reproducibility (RSD, $n=5$ ) were in the range of $42-166,0.9169-$ 0.9976 , and $2.8-12 \%$, respectively. Considering that IL can be easily prepared from relatively inexpensive materials and tuned by combination of different anions and cations for task-specific extraction of analytes from various solvent media, this proposed method should have great potentiality in sample preparation. Furthermore, the nonvolatility of IL makes it potentially useful for headspace LPME of volatile analytes.

Ionic liquids (IL) are ionic media resulting from combinations of organic cations and various anions. They may be liquids at room temperature. Their use as novel solvent systems for organic synthesis and catalysis has received a good deal of attention. ${ }^{1} \mathrm{IL}$ have several unique properties that make them useful in a variety of chemical processes. For example, they have no effective vapor

\footnotetext{
* Corresponding author. Fax: 8610-62849179, E-mail: gbjiang@mail.rcees.ac.cn

+ Chinese Academy of Sciences.

₹ Shandong University.

(1) Welton, T. Chem. Rev. 1999, 99, 2071-2083.
}

pressure, the viscosity and the miscibility in water and other organic solvents can be tuned by changing the combination of different anions and cations of $\mathrm{IL}$, and the preparation is easy from relatively inexpensive materials. ${ }^{1,2} \mathrm{As}$ a result of these properties, $\mathrm{IL}$ is emerging as an alternative recyclable medium for separation. Recently, IL were considered as attractive water-immiscible phases in liquid-liquid extraction..$^{3-5} \mathrm{IL}$ were also used in organic solvent-supercritical $\mathrm{CO}_{2}$ biphasic extractions ${ }^{6-8}$ and in pervaporation. 4,9

By using two typical IL, 1-butyl-3-methylimidazolium hexafluorophosphate ([ $\left.\left.\mathrm{C}_{4} \mathrm{M} I \mathrm{M}\right]\left[\mathrm{PF}_{6}\right]\right)$ and the analogous chloride salt ([ $\mathrm{C}_{4-}$ $\mathrm{MIM}] \mathrm{Cl}$ ), as stationary phases for gas chromatography, Armstrong et al..$^{10}$ studied the interactive and retentive behaviors of various compounds with IL. It was observed that the $\left[\mathrm{C}_{4} \mathrm{M} I \mathrm{M}\right] \mathrm{Cl}$ interacted much more strongly with proton-donor and -acceptor molecules, while the $\left[\mathrm{C}_{4} \mathrm{MIM}\right]\left[\mathrm{PF}_{6}\right]$ tended to interact more strongly with nonpolar solutes. M ore recently, Armstrong et al. ${ }^{11}$ used a linear free energy approach to characterize IL and provided data that could be applied to help identify interactions and properties that are important for specific chemical applications.

Branco et al. ${ }^{12}$ reported a novel method for highly selective separation of organic compounds by using a supported liquid membrane based on IL. Using [ $\left.\mathrm{C}_{4} \mathrm{M} I \mathrm{M}\right]\left[\mathrm{PF}_{6}\right]$ supported by a poly(vinylidene fluoride) microporous membrane, diisopropylamine was selectively separated from a mixture of the organic isomeric

(2) Wilkes, J. S.; Zaworotko, M. J. J. Chem. Soc., Chem. Commun. 1992, 965967.

(3) Huddleston, J. G.; Willauer, H. D.; Swatloski, R. P.; Visser, A. E.; Rogers, R. D. Chem. Commun. 1998, 1765-1766.

(4) Fadeev, A. G.; M eagher, M. M. Chem. Commun. 2001, 295-296.

(5) Visser, A. E.; Swatloski, R. P.; Reichert, W. M.; M ayton, R. S.; Sheff, Wierzbicki, A.; Davies, J. H.; Rogers, R. D. Chem. Commun. 2001, 135136.

(6) Blanchard, L. A.; Hancu, D.; Beckman, E. J.; Brennecke, J. F. Nature 1999 399, 28-29.

(7) Brown, R. A.; Pollet, P.; M ckoon, E.; Eckert, C. A.; Liotta, C. L.; J essop, P. G. J. Am. Chem. Soc. 2001, 123, 1254-1255.

(8) Boesmann, A. Francio, G.; Janssen, E.; Solinas, M.; Leitner, W.; Wasserschetd, P. Angew. Chem., Int. Ed. 2001, 40, 2697-2699.

(9) Schafer, T.; Rodrigues, C. M.; Afonso, C. A. M.; Crespo, J. G. Chem. Commun. 2001, 1622-1623.

(10) Armstrong, D. W.; He, L.; Liu, Y.-S. Anal. Chem. 1999, 71, 3873-3876.

(11) Armstrong, D. W.; Anderson, J. L.; Ding, J.; Welton, T. J. Am. Chem. Soc. 2002, 124, 14247-14254.

(12) Branco, L. C.; Crespo, J. G.; Afonso, C. A. M. Angew. Chem., Int. Ed. 2002, 41, 2771-2773.

10.1021/ac034506m CCC: $\$ 25.00$ @ 2003 American Chemical Society Published on Web 09/04/2003 
amines hexylamine, diisopropylamine, and triethylamine in diethyl ether.

Furthermore, Visser et al. ${ }^{13}$ prepared a series of task-specific $\mathrm{IL}$ for liquid-liquid extraction of $\mathrm{Hg}^{2+}$ and $\mathrm{Cd}^{2+}$ from water. By appending urea-, thiourea-, and thioether-substituted alkyl groups to imidazoles and combining the resulting cationic species with $\mathrm{PF}_{6}{ }^{-}, \mathrm{IL}$ phases are prepared into which $\mathrm{Hg}^{2+}$ and $\mathrm{Cd}^{2+}$ can be extracted with distribution ratios increased by several orders of magnitude. In a report by Huddleston et al.,14 a series of hydrophilic and hydrophobic IL resulting from [ $\left.\mathrm{C}_{n} \mathrm{MIM}\right](\mathrm{n}=4$, 6,8 ) cations and different anions were prepared and characterized to determine how water content, density, viscosity, surface tension, melting point, and thermal stability are affected by changes in alkyl chain length and anion. Abraham et al. correlated the partition coefficients $(\log P)$ between water and two IL with Abraham's solute descriptors to yield a linear free energy relationship. These can be used to predict further values of log $P$, to ascertain the solute properties that lead to increased or decreased $\log P$, and to characterize the partition systems. ${ }^{15}$

$\mathrm{M}$ ore recently, Carda-Broch et al. ${ }^{16}$ studied in detail the solvent properties of $\left[\mathrm{C}_{4} \mathrm{M} I \mathrm{M}\right]\left[\mathrm{PF}_{6}\right]$ and determined the $\left[\mathrm{C}_{4} \mathrm{M} I \mathrm{M}\right]\left[\mathrm{PF}_{6}\right] /$ water and $\left[\mathrm{C}_{4} \mathrm{M} I \mathrm{M}\right]\left[\mathrm{PF}_{6}\right] /$ heptane distribution coefficients for a set of 40 compounds, including organic acids, organic bases, amino acids, antioxidants, and neutral compounds.

The majority of the studies related to IL focus on their potential use in industrial processes, and limited efforts have been made to apply IL to analytical chemistry purposes. Shetty et al. ${ }^{17}$ studied the applicability of alkylammonium nitrate and thiocyanate as a mobile phase in microcolumn reversed-phase liquid chromatography. Armstrong et al. adopted IL as stationary phases for gas chromatography ${ }^{10,18}$ and as matrixes for matrix-assisted laser desorption/ ionization mass spectrometry. ${ }^{19} \mathrm{IL}$ were also used as running electrolytes in aqueous ${ }^{20}$ and nonaqueous ${ }^{21,22}$ capillary electrophoresis, and an IL-coated capillary was prepared and investigated for DNA separation. ${ }^{23}$ Chun et al. ${ }^{24}$ reported the influence of structural variation in IL on the selectivity and efficiency of competitive alkali metal salt extraction by a crown ether.

Sample preparation is currently a bottleneck of analytical chemistry. Although most sample preparation can be accomplished by conventional procedures such as liquid-liquid extraction and solid-phase extraction (SPE), these methods suffer from

(13) Visser, A. E.; Swatloski, R. P.; Reichert, W. M.; Mayton, R.; Sheff, S.; Wierzbicki, A.; Davies, J. H.; Rogers, R. D. Environ. Sci. Technol. 2002, 36, 2523-2529.

(14) Huddleston, J. G.; Visser, A. E.; Reichert, W. M .; Willauer, H. D.; Broker, G. A.; Rogers, R. D. Green Chem. 2001, 3, 156-164.

(15) Abraham, M. H.; Zissimos, A. M .; Huddleston, J. G.; Willauer, H. D.; Rogers, R. D.; Acree, W. E., Jr. Ind. Eng. Chem. Res. 2003, 42, 413-418.

(16) Carda-Broch, S.; Berthod, A.; Armstrong, D. W. Anal. Bioanal. Chem. 2003, 375, 191-199.

(17) Shetty, P. H.; Youngberg, P. J.; Kersten, B. R.; Poole, C. F. J. Chromatogr. 1987, 411, 61-79.

(18) Berthod, A.; He, L.; Armstrong, D. W. Chromatographia 2000, 53, 63-68.

(19) Armstrong, D. W.; Zhang, L.-K.; He, L.; Gross, M. L. Anal. Chem. 2001, 73, 3679-3686.

(20) Yanes, E. G.; Gratz, S. R.; Baldwin, M. J.; Robinson, S. E.; Stalcup, A. M. Anal. Chem. 2001, 73, 3838-3844.

(21) Vaher, M .; Koel, M .; Kaljurand, M. Chromatographia 2001, 53, S-302-S306.

(22) Vaher, M .; Koel, M .; Kaljurand, M. Electrophoresis 2002, 23, 426-430.

(23) Qin, W.; Li, S. F. Y. Analyst 2003, 128, 37-41.

(24) Chun, S.; Dzyuba, S. V.; Bartsch, R. A. Anal. Chem. 2001, 73, 3737-3741. the disadvantages of being time-consuming, using large amounts of toxic organic solvent, and being relatively expensive. Therefore, many efforts have been made to develop sample preparation methods that can overcome these disadvantages.

Recently, liquid-phase microextraction (LPME) has emerged as an attractive alternative for sample preparation. LPME can be performed by using a single drop of solvent ${ }^{25-34}$ or a small length of porous hollow fiber-protected solvent. ${ }^{35-37}$ LPM E is commonly conducted in direct-immersion mode, but headspace extraction is also possible. 25,34,37 It has been demonstrated that LPM E shows comparable extraction efficiency and reproducibility as the widely used solid-phase microextraction technique. The advantage of LPME is that it is inexpensive and there is considerable freedom in selecting appropriate solvents for extraction of different analytes.

The objective of this study is to exploit the potentiality of IL in sample preparation using the LPME technique. Considering that naphthalene $\mathrm{e}^{10}$ and fluoranthen $\mathrm{e}^{15}$ have relative large partition coefficients in the $\left[\mathrm{C}_{n} \mathrm{MIM}\right]\left[\mathrm{PF}_{6}\right] /$ water $(n=4,6)$ systems, IL drop-based direct-immersion and headspace LPME procedures were tried for extraction of polycyclic aromatic hydrocarbons (PAHs) from aqueous samples.

\section{EXPERIMENTAL SECTION}

Reagents. A mixed-PAH standard containing the Environmental Protection Agency (EPA) priority 16 PAHs was purchased from AccuStandard Inc. (N ew Haven, CT).An individual standard of benzo[k]fluoranthene and a mixed standard of fluorene, phenanthrene, and fluoranthene were obtained from Institute for Reference $M$ aterials of SEPA (Beijing, China). 1-M ethylimidazole (99\%), 1-chlorobutane (99\%), 1-chlorohexane (95\%), 1-chloroctane $(99 \%$, and hexafluorophosphoric acid ( 60 wt \%solution in water) were obtained from Acros Organics (Geel, Belgium). HPLC-grade methanol and acetonitrile were purchased from Scharlace Chemie SA (B arcelona, Spain). All other chemicals were of analytical grade (Beijing Chemicals Corp., Beijing, China), and ultrapure water (EASY pure LF) was used throughout.

IL Synthesis. The syntheses of 1-butyl-3-methylimidazolium hexafluorophosphate $\left[\mathrm{C}_{4} \mathrm{M} I \mathrm{M}\right]\left[\mathrm{PF}_{6}\right]$, 1-hexyl-3-methylimidazolium hexafluorophosphate $\left(\left[\mathrm{C}_{6} \mathrm{M} I \mathrm{M}\right]\left[\mathrm{PF}_{6}\right]\right)$, and 1-octyl-3-methylimidazolium hexafluorophosphate $\left(\left[\mathrm{C}_{8} \mathrm{M} I \mathrm{M}\right]\left[\mathrm{PF}_{6}\right]\right)$ were conducted as described elsewhere. ${ }^{2,3,10,38}$ B riefly, $\left[\mathrm{C}_{4} \mathrm{M}\right.$ IM ] CI was prepared by adding equal amounts $(0.2 \mathrm{~mol})$ of 1-methylimidazole and 1-chlorobutane to a round-bottomed flask fitted with a reflux condenser and reacting for $48 \mathrm{~h}$ at $70{ }^{\circ} \mathrm{C}$. $\left[\mathrm{C}_{6} \mathrm{MIM}\right] \mathrm{Cl}$ and $\left[\mathrm{C}_{8-}\right.$ $\mathrm{MIM}] \mathrm{Cl}$ were prepared by microwave synthesis in the following way: ${ }^{8}$ (i) mixing $2 \mathrm{mmol}$ of 1-methylimidazole and 1-chlorohexane

(25) Liu, S.; Dasgupta, P. K. Anal. Chem. 1995, 67, 2042-2049.

(26) Cardoso, A. A.; Dasgupta, P. K. Anal. Chem. 1995, 67, 2562-2566.

(27) Jeannot, M. A.; Cantwell, F. F. Anal. Chem. 1996, 68, 2236-2240.

(28) Jeannot, M. A.; Cantwell, F. F. Anal. Chem. 1997, 69, 235-239.

(29) He, Y.; Lee, H. K. Anal. Chem. 1997, 69, 4634-4640.

(30) Wang, Y.; Yien, C. K. He, Y.; Lee, H. K. Anal. Chem. 1998, 70, 4610-4614.

(31) M a, M. H.; Cantwell, F. F. Anal. Chem. 1998, 70, 3912-3919.

(32) M a, M. H.; Cantwell, F. F. Anal. Chem. 1999, 71, 388-393.

(33) Genfa, Z.; Dasgupta, P. K. Anal. Chem. 2000, 72, 3165-3170.

(34) Theis, A. L.; Waldadack, A. J.; Hansen, S. M .; Jannot, M. A. Anal. Chem. 2001, 73, 5651-5654.

(35) Pedersen-Bjergaard, S.; Rasmussen, K. E. Anal. Chem. 1999, 71, 26502656.

(36) Zhao, L.; Lee, H. K. Anal. Chem. 2002, 74, 2486-2492.

(37) Shen, G.; Lee, H. K. Anal. Chem. 2003, 75, 98-103.

(38) Varma, R. S.; Namboodiri, V. V. Chem. Commun. 2001, 643-644. 
Table 1. Some Physicochemical Properties of the Studied IL and 1-Octanol

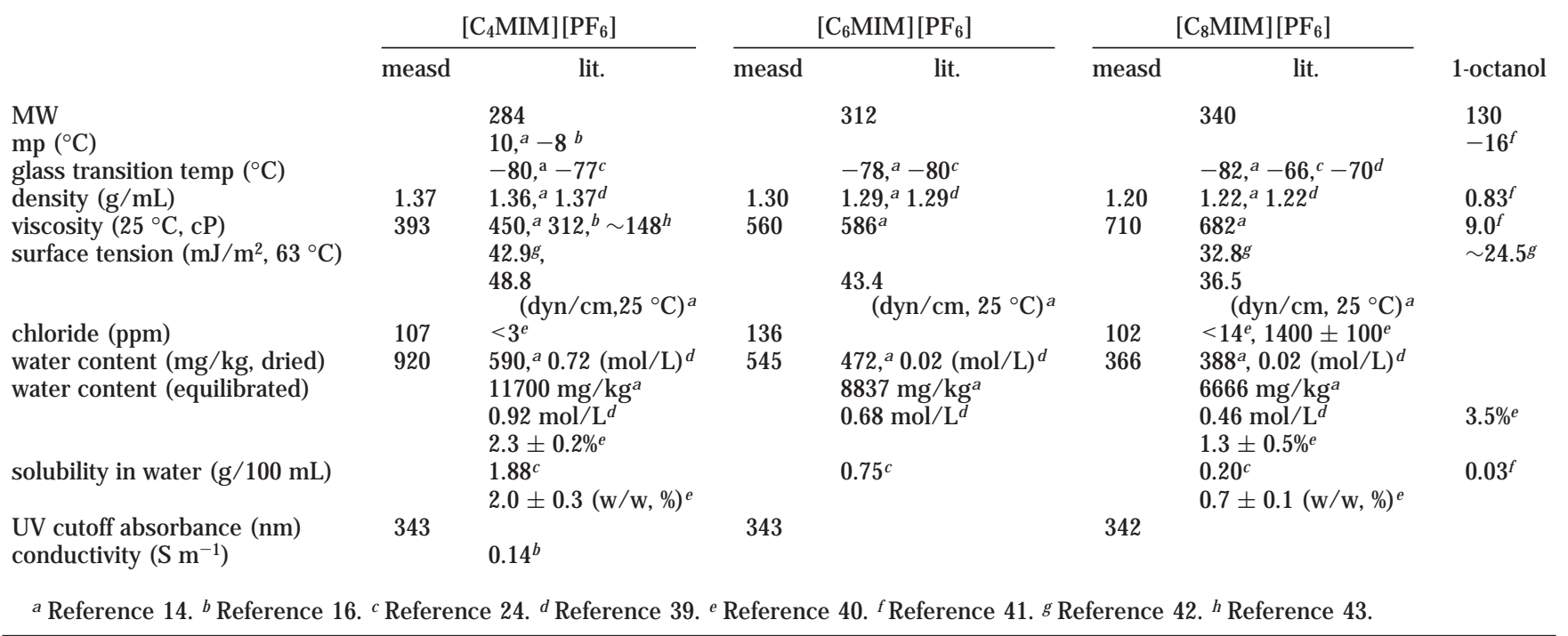

Table 2. UV and Fluorescence (FL) Detection Conditions for HPLC Determination of PAHs

\begin{tabular}{|c|c|c|c|c|c|}
\hline & analyte & & & $\mathrm{FL}$ & $\mathrm{nm})$ \\
\hline no. & name & $(\min )$ & $(\mathrm{nm})$ & excitn & emissn \\
\hline 1 & naphthalene & 0 & 254 & 218 & 357 \\
\hline 2 & acenaphthylene & & 254 & & \\
\hline 3 & acenaphthene & 19.00 & 254 & 226 & 359 \\
\hline 4 & fluorene & & & & \\
\hline 5 & phenanthrene & 23.20 & & 250 & 350 \\
\hline 6 & anthracene & 24.20 & & 250 & 425 \\
\hline 7 & fluoranthene & 25.85 & & 234 & 440 \\
\hline 8 & pyrene & & & & \\
\hline 9 & $\begin{array}{l}\text { benz[a]anthracene, } \\
\text { chrysene }\end{array}$ & 29.00 & & 286 & 405 \\
\hline 10 & benzo[b]fluoranthene & 32.21 & & 250 & 420 \\
\hline 11 & benzo[k]fluoranthene & & & & \\
\hline 12 & benzo[a]pyrene & 35.00 & & 294 & 460 \\
\hline 13 & $\begin{array}{c}\text { dibenz }[a, h] \text { anthracene, } \\
\text { benzo[ghi ] perylene }\end{array}$ & 36.10 & & 298 & 420 \\
\hline 14 & indenol[ $1,2,3-c d]$ pyrene & 38.00 & & 246 & 490 \\
\hline
\end{tabular}

or 1-chloroctane in test tube, which is put in a household microwave oven; (ii) irradiating the mixture for $30 \mathrm{~s}$ at $240 \mathrm{~W}$; (iii) mixing again outside the oven for $10 \mathrm{~s}$ and then heating at the same power level for an additional $15 \mathrm{~s}$. Step iii was repeated until the formation of a clear single IL phase. The produced $\left[\mathrm{C}_{\mathrm{n}}\right.$ $\mathrm{MIM}] \mathrm{Cl}(\mathrm{n}=4,6,8)$ were washed with ether and dried under vacuum at $80^{\circ} \mathrm{C}$.

$\left[\mathrm{C}_{n} \mathrm{M} I \mathrm{M}\right]\left[\mathrm{PF}_{6}\right](\mathrm{n}=4,6,8)$ were prepared by slowly adding hexafluorophosphoric acid $(0.13 \mathrm{~mol})$ to the corresponding chloride $(0.1 \mathrm{~mol})$ in $100 \mathrm{~mL}$ of water. After stirring for $12 \mathrm{~h}$, the lower liquid portion was washed with water until the washings were no longer acidic. The IL were cleaned up with $\mathrm{Al}_{2} \mathrm{O}_{3}$ and dried under vacuum at $80^{\circ} \mathrm{C}$. Caution: Hexafluorophosphoric acid is corrosive and toxic and must be handled with care, and the hydrolytic instability of $\left[\mathrm{C}_{n} \mathrm{M} I \mathrm{M}\right]\left[\mathrm{PF}_{6}\right]$ should also be considered.

Physicochemical Property. The obtained three IL were all colorless viscous liquids with physicochemical properties shown in Table 1. The density was determined by taking $50 \mu \mathrm{L}$ of IL into a weighted vial with a $100-\mu \mathrm{L}$ HPLC microsyringe to quantify its weight. The water content was determined using Karl Fischer titration. The viscosity was measured by a viscosity meter. The chloride content was determined with a modified spectrophotometric method. ${ }^{44}$ Our experiment demonstrated that IL interfered with the spectrophotometric determination of chloride; thus, a standard addition procedure was adopted. The UV cutoff absorbance was determined by HPLC with an SPD-M 10Avp diode array detector (Shimadzu).

It is clear from Table 1 that the three IL synthesized were not pure, and it should be noted that impurities such as the presence of chloride and nonequilibrated water would influence the physicochemical properties of the $\mathrm{IL}$, as well as the partitioning and enrichment of PAHs. ${ }^{43}$ Since the purpose of our study is to use IL for enrichment of PAHs (a set of stable analytes) for analytical purposes, the influence of the IL impurities on enrichment should be the same for samples and standards and could thus be eliminated. Therefore, no efforts were made to further purify our synthesized IL.

Instrument. The HPLC equipment used was an Agilent 1100LC including a BinPump, a VWD detector, and a FLD detector. For all compounds of interest, the VWD detector was set at 254-nm wavelength, and the excitation and the emission wavelength of the fluorescence detector was set as shown in Table 2. A personal computer equipped with an Agilent ChemStation program for LC systems was used to process chromatographic data. An Agilent Zorbax Eclipse XDB- ${ }_{18}$ column ( $150 \times 4.6$ mm, particle size $5 \mu \mathrm{m}$ ) was used as the analytical column.

Extraction Procdure. For the direct-immersion LPME procedure, $3 \mu \mathrm{L}$ of $\mathrm{IL}$ was aspirated into a $50-\mu \mathrm{L}$ microsyringe (Agilent), which was clamped so that the needle of the syringe was immersed into the $15-\mathrm{mL}$ sample solution held in a vial. Then

(39) Visser, A. E.; Swatloski, R. P.; Reichert, W. M .; Griffin, S. T.; Rogers, R. D. Ind. Eng. Chem. Res. 2000, 39, 3596-3604.

(40) Anthony, J. L.; M aginn, E. J.; Brennecke, J. F. J. Phys. Chem. B 2001, 105, 10942-10949.

(41) M erck database, hettp:/ / chemdat.merk.de/

(42) Law, G.; Watson, P. R. Langmuir 2001, 17, 6138-6141.

(43) Seddon, K. R.; Stark, A.; Torres, M.-J. Pure Appli. Chem. 2000, 72, 22752287.

(44) Florence, T. M .; Farrar, Y. J. Anal. Chim. Acta 1971, 54, 373-377.

5872 Analytical Chemistry, Vol. 75, No. 21, November 1, 2003 


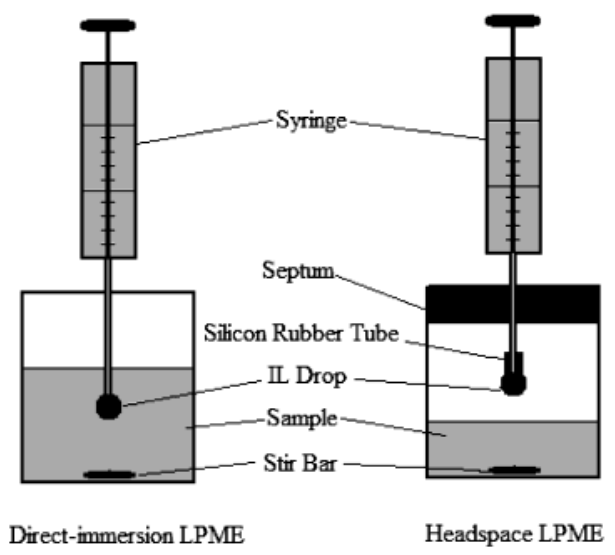

Figure 1. Schematic diagram of the two different versions of liquidphase microextraction (LPME).

the plunger was depressed to expose a 3- $\mu \mathrm{L} I \mathrm{~L}$ drop to the sample solution and the magnetic stirrer turned on. After stirring for the prescribed time, the IL drop was retracted into the microsyringe and injected into the HPLC system for analysis.

For the headspace LPM E procedure, $10 \mathrm{~mL}$ of sample solution was placed in a 15-mL vial with septum. After the aspiration of 3 $\mu \mathrm{L}$ of IL, the needle of the microsyringe was used to pierce the vial septum, and the microsyringe was clamped into place so that the needle of the syringe was located in a consistent position of the headspace. Then the extraction was conducted as described above for immersed LPME. To suspend a 3- $\mu \mathrm{L} I \mathrm{~L}$ drop, the tip of the microsyringe needle was sheathed with a 3-mm-long silicon rubber tube (0.2-mm i.d and 2.8-mm o.d) as shown in Figure 1.

HPLC Separation. HPLC separation of PAHs was conducted by using a mixture of acetonitrile and water as mobile phase at a flow rate of $0.8 \mathrm{~mL} / \mathrm{min}$. The gradient profile was as follows: $40 \%$ acetonitrile for $0-5 \mathrm{~min}$, increase to $85 \%$ acetonitrile during 5-25 $\mathrm{min}$, and then to $100 \%$ acetonitrile during $25-40 \mathrm{~min}$. Under these conditions, 12 PAHs were baseline separated. B enz[a] anthracene and chrysene, as well as dibenz[a,h]anthracene and benzo[ghi]perylene, were coeluted because of the relatively short analytical column,. Therefore, the 12 PAHs shown in Table 1 were investigated in the following study.

\section{RESULTS AND DISCUSSION}

Two modes of LPM E, direct-immersion LPM E and headspace LPM E, were investigated. Some parameters of the direct-immersion LPME such as type of IL, solvent drop volume, and extraction time were optimized using a mixed standard containing $1 \mu \mathrm{g} / \mathrm{L}$ (excepting specified) each of fluorene, phenanthrene, fluoranthene, and benzo[k]fluoranthene as model compounds. Then, the direct-immersion LPM E was evaluated on the basis of enrichment factor, reproducibility, and linearity for the EPA priority PAHs.

Selection of IL. The alkyl part of the 1-alkyl-3-methylimidazolium hexafluorophosphate has significant influence on its physical and chemical properties, such as density, viscosity, and solubility, ${ }^{14}$ that might affect the extraction efficiency of target analytes. Therefore, in this study, three IL including $\left[\mathrm{C}_{4} \mathrm{MIM}\right]$ $\left[\mathrm{PF}_{6}\right],\left[\mathrm{C}_{6} \mathrm{MIM}\right]\left[\mathrm{PF}_{6}\right],\left[\mathrm{C}_{8} \mathrm{MIM}\right]\left[\mathrm{PF}_{6}\right]$, and 1-octanol were compared as extraction solvents.

The experiments demonstrated that the largest drop volume that could be stably suspended on the needle tip of microsyringe
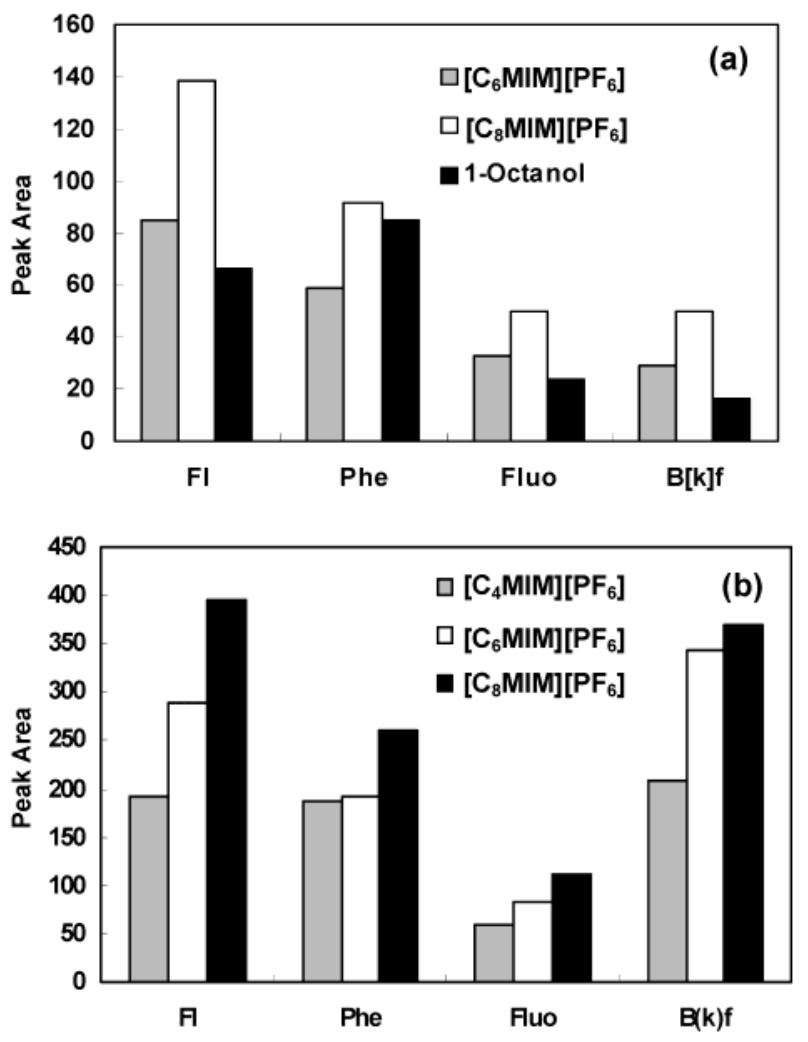

Figure 2. Effect of various solvents on the peak area of PAHs: (a) $5 \mu \mathrm{g} / \mathrm{L}$ PAHs extracted for 5 min using $1 \mu \mathrm{L}$ of solvent; (b) $1 \mu \mathrm{g} / \mathrm{L}$ PAHs extracted for 30 min using $3 \mu \mathrm{L}$ of $\mathrm{IL}$. FI, fluorene; Phe, phenanthrene; Fluo, fluoranthene; $\mathrm{B}[k] \mathrm{f}$, benzo[ $k]$ fluoranthene.

was $3 \mu \mathrm{L}$ for IL and $1 \mu \mathrm{L}$ for 1 -octanol. Therefore, a drop volume of $1 \mu \mathrm{L}$ was adopted for comparing the enrichment efficiency of $5 \mu \mathrm{g} / \mathrm{L}$ PAHs by using IL and 1-octanol as extraction solvent with an extraction time of $5 \mathrm{~min}$. The results shown in Figure $2 \mathrm{a}$ indicate that $\left[\mathrm{C}_{8} \mathrm{M} I \mathrm{M}\right]\left[\mathrm{PF}_{6}\right]$ provided the largest peak area for all the studied PAHs. The result of $\left[\mathrm{C}_{4} \mathrm{MIM}\right]\left[\mathrm{PF}_{6}\right]$ was not shown as a $1-\mu \mathrm{L}$ droplet of $\left[\mathrm{C}_{4} \mathrm{MIM}\right]\left[\mathrm{PF}_{6}\right]$ dissolved completely into the sample solution in 5-min extraction. Therefore, a 3- $\mu \mathrm{L}$ droplet was used for further comparing the enrichment of $1 \mu \mathrm{g} / \mathrm{L}$ PAHs by using the three IL as extraction solvent, and the results are shown in Figure $2 \mathrm{~b}$. Although Figure $2 \mathrm{~b}$ shows that the largest analytical signals (peak area) were obtained when $\left[\mathrm{C}_{8} \mathrm{MIM}\right]\left[\mathrm{PF}_{6}\right]$ was employed, it does not mean that the partition coefficients of $\mathrm{PAHS}$ in the $\left[\mathrm{C}_{8} \mathrm{M} I \mathrm{M}\right]\left[\mathrm{PF}_{6}\right] /$ water system are larger than the other systems. This is because LPME is a nonequilibrium procedure, and the obtained peak area is a complex result of various parameters including partition coefficient, the diffusion coefficient of the solute, the solubility of the extraction solvent in the sample solution, and the viscosity of both sample solution and solvent. Abraham et al..$^{15}$ calculated the partition coefficients $(\log P)$ of fluoranthene to be 4.22 and 3.75 for the $\left[\mathrm{C}_{4} \mathrm{MIM}\right]\left[\mathrm{PF}_{6}\right] /$ water and $\left[\mathrm{C}_{6} \mathrm{M} I \mathrm{M}\right]\left[\mathrm{PF}_{6}\right] /$ water system, respectively. However, the results shown in Figure $2 \mathrm{~b}$ indicate that the obtained peak area varied in the sequence $\left[\mathrm{C}_{4} \mathrm{M} I \mathrm{M}\right]\left[\mathrm{PF}_{6}\right]<\left[\mathrm{C}_{6} \mathrm{M} I \mathrm{M}\right]\left[\mathrm{PF}_{6}\right]<\left[\mathrm{C}_{8} \mathrm{M} I \mathrm{M}\right]\left[\mathrm{PF}_{6}\right]$. The major reason is that the solubility of these $\mathrm{IL}$ varies in the same sequence (Table 1). It was observed in our experiments that, after 30 min of extraction, the volume of the survived IL droplet varied in the sequence $\left[\mathrm{C}_{4} \mathrm{MIM}\right]\left[\mathrm{PF}_{6}\right]<\left[\mathrm{C}_{6} \mathrm{M} I \mathrm{M}\right]\left[\mathrm{PF}_{6}\right]$ $<\left[\mathrm{C}_{8} \mathrm{MIM}\right]\left[\mathrm{PF}_{6}\right]$. From an analytical chemistry point of view, a 


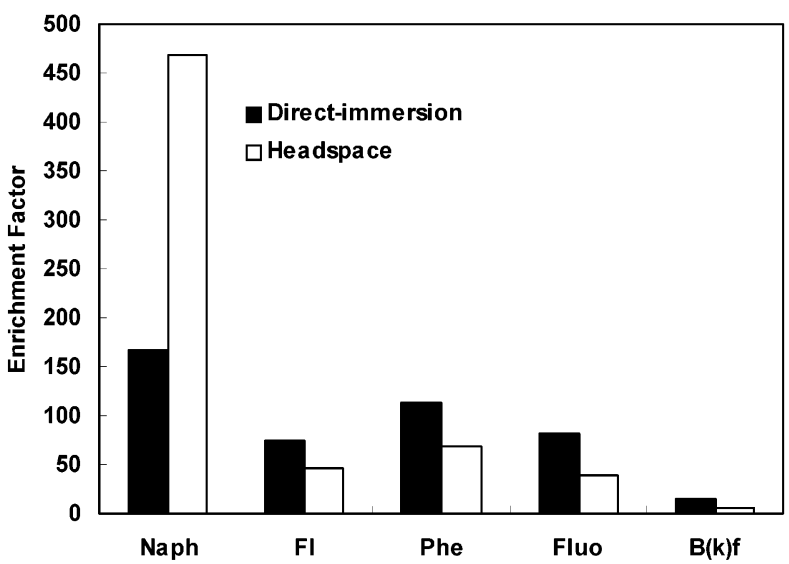

Figure 3. Comparison of enrichment factor between the directimmersion and the headspace LPME of PAHs. Sample: $10 \mathrm{~mL}$ of 5 $\mu \mathrm{g} / \mathrm{L}$ spiked PAHs in aqueous solution. Extractant: $3 \mu \mathrm{L}$ of [ $\left.\mathrm{C}_{8} \mathrm{MIM}\right]-$ $\left[\mathrm{PF}_{6}\right]$ drop. Extraction time: $30 \mathrm{~min}$. Naph, naphthalene; Fl, fluorene; Phe, phenanthrene; Fluo, fluoranthene; $\mathrm{B}[k] \mathrm{f}$, benzo[k]fluoranthene.

larger peak area is desirable to get a lower detection limit. Thus, $\left[\mathrm{C}_{8} \mathrm{MIM}\right]\left[\mathrm{PF}_{6}\right]$ was selected as extraction solvent in the following studies.

Extraction Mode. LPME can be conducted in two modes, direct-immersion and the headspace extraction. One unique property of IL is that they have no effective vapor pressure even at high temperature. Therefore, it is reasonable to employ IL as extraction solvent for headspace LPM E as the IL droplet exposed to the headspace can survive for a long time, permitting longterm extractions. The applicability of $\left[\mathrm{C}_{8} \mathrm{MIM}\right]\left[\mathrm{PF}_{6}\right]$ for headspace LPME was evaluated by using naphthalene, fluorene, phenanthrene, fluoranthene, and benzo[k]fluoranthene as model compounds. Figure 3 compares the enrichment factor of the two extraction modes when samples spiked with $5 \mu \mathrm{g} / \mathrm{L}$ PAHs were extracted with $3 \mu \mathrm{L}$ of [ $\left.\mathrm{C}_{8} \mathrm{MIM}\right]\left[\mathrm{PF}_{6}\right]$ during extraction time of $30 \mathrm{~min}$ at room temperature $\left(20^{\circ} \mathrm{C}\right)$. As can be seen, for the lowvolatility PAHs, the enrichment factor of headspace LPME was significantly lower than that of direct-immersion mode and the difference increased with increasing $\mathrm{PAH}$ molecular weight as expected. For the extraction of naphthalene, however, the enrichment factor by headspace LPME was almost 3-fold that of directimmersion LPME. There are two reasons that might explain the much higher enrichment factor of headspace LPME of naphthalene. At first, there is no loss of [ $\left.\mathrm{C}_{8} \mathrm{M} I \mathrm{M}\right]\left[\mathrm{PF}_{6}\right]$ in headspace LPM E during extraction as IL dose not evaporate. In direct-immersion $L P M E$, some of the $\left[\mathrm{C}_{8} M I M\right]\left[\mathrm{PF}_{6}\right]$ is lost as it dissolves slightly in aqueous sample solution. The second reason is that headspace LPM E shows a larger extraction rate as the extract needs not be transported through a liquid-liquid interface, which is the ratedetermining factor in the direct-immersion procedure.

Considering that it could provide a higher enrichment factor for most PAHs, the direct-immersion LPME mode was adopted in the following study. However, it should be emphasized that the use of IL for headspace LPME of volatile compounds is a potentially useful application area demanding further investigation.

Extraction Time. Experiments showed that when a $3-\mu \mathrm{L}$ droplet of $\left[\mathrm{C}_{8} \mathrm{MIM}\right]\left[\mathrm{PF}_{6}\right]$ was suspended on the needle of a microsyringe and immersed in a 20-mL sample solution for extraction, the longest possible extraction time was $60 \mathrm{~min}$. With

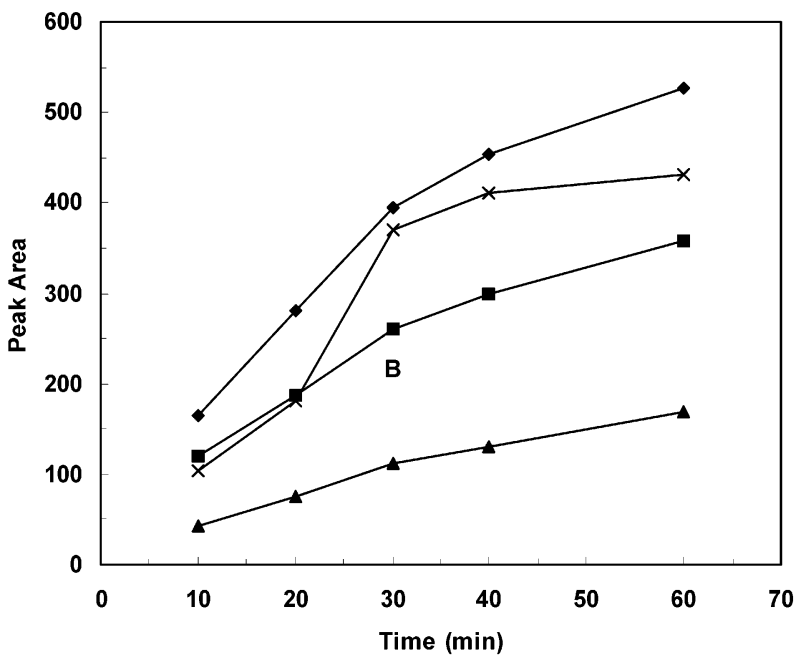

Figure 4. Influence of extraction time volume on the peak area of PAHs. Sample: $20 \mathrm{~mL} 1 \mu \mathrm{g} / \mathrm{L}$ spiked PAHs in aqueous solution. Extractant: $3-\mu \mathrm{L}\left[\mathrm{C}_{8} \mathrm{MIM}\left[\mathrm{PF}_{6}\right]\right.$ drop. $\bullet$, fluorene; $\mathbf{\square}$, phenanthrene; $\Delta$, fluoranthene; $\times$, benzo[ $k$ fluoranthene.

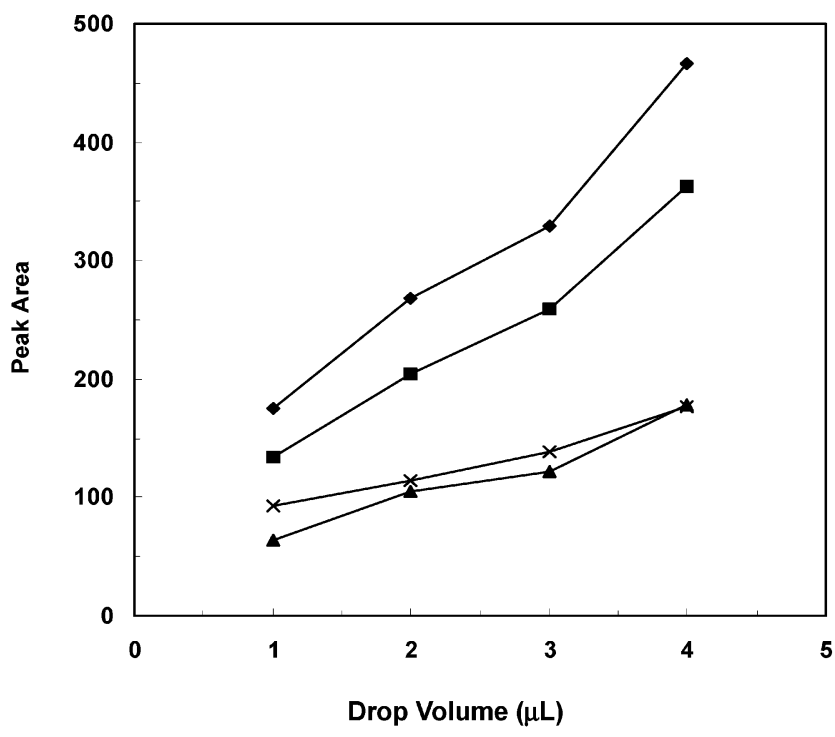

Figure 5. Effect of drop volume on the peak area of PAHs. Sample: $20 \mathrm{~mL} 1 \mu \mathrm{g} / \mathrm{L}$ spiked PAHs in aqueous solution. Extraction time: 30 min. $\bullet$, fluorene; $\mathbf{\square}$, phenanthrene; $\mathbf{\Delta}$, fluoranthene; $\times$, benzo[k]fluoranthene.

longer extraction times, the peak area decreased significantly and the reproducibility was lost, as most of the IL was dissolved in the sample solution. Figure 4 shows the influence of extraction time on the peak area of PAHs when a $3-\mu \mathrm{L}$ droplet of $\left[\mathrm{C}_{8} \mathrm{M} I \mathrm{M}\right]$ $\left[\mathrm{PF}_{6}\right]$ was used as extractant. As can be seen, the peak area increased with enrichment time over the whole range of $10-60$ $\min$.

In the following study, the enrichment time was set to $30 \mathrm{~min}$. But according to Figure 4, an extraction time up to 60 min could be adopted if a larger enrichment factor is desired.

Drop Volume. The effect of [ $\left.\mathrm{C}_{8} \mathrm{M} I \mathrm{M}\right]\left[\mathrm{PF}_{6}\right]$ drop volume on the HPLC peak area was studied by exposing a drop to aqueous sample solution for $30 \mathrm{~min}$. Results shown in Figure 5 indicate that the peak area increased with the drop volume over the range of $1-4 \mu \mathrm{L}$. Since the proposed LPME is a nonequilibrium procedure, the enrichment is a diffusion-controlled interfacial 


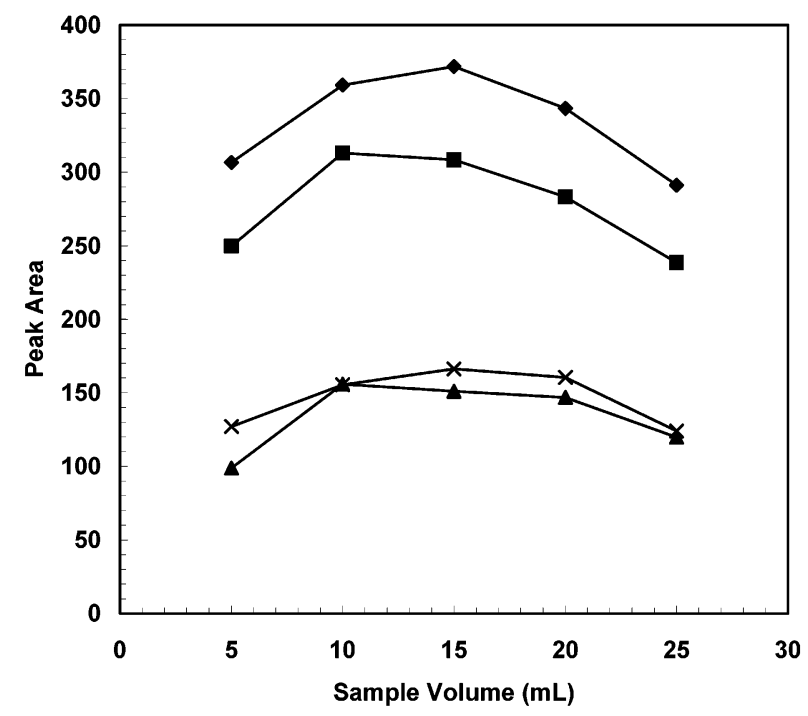

Figure 6. Effect of sample volume on the peak area of PAHs. Sample: $1 \mu \mathrm{g} / \mathrm{L}$ spiked PAHs in aqueous solution. Extractant: $3 \mu \mathrm{L}$ of $\left[\mathrm{C}_{8} \mathrm{MIM}\right]\left[\mathrm{PF}_{6}\right]$ drop. Extraction time: $30 \mathrm{~min}$. $\bullet$, fluorene; $\mathbf{\square}$ phenanthrene; $\boldsymbol{\Lambda}$, fluoranthene; $\times$, benzo[ $k]$ fluoranthene.

phenomenon. Therefore, as the drop surface increases with the drop volume, this results in a larger peak area. Figure 5 also shows that the lower the molecular weight of PAHs the more significant the increase in peak area. This probably is due to the diffusion rate of the PAH molecules, which decrease with molecular weight. Although a 4- $\mu$ L drop gave larger peak area, it was occasionally dislodged by the stirred aqueous sample solution. A drop of $3 \mu \mathrm{L}$ of $\left[\mathrm{C}_{8} \mathrm{MIM}\right]\left[\mathrm{PF}_{6}\right]$ was adopted in the following study as it could stably persist on the needle of the syringe.

Sample Volume. Figure 6 shows the relationship between the peak area and the sample volume, which indicates that for the four studied PAHs the largest analytical response was obtained when $10-15 \mathrm{~mL}$ of sample was extracted. A larger sample volume gave a smaller peak area because more $\left[C_{8} M I M\right]\left[P_{6}\right]$ was dissolved into the sample solution, leaving less residual $\mathrm{IL}$ to be injected into the HPLC system for detection.

Addition of Organic Solvent. Due to the low aqueous solubility of PAHs, an organic solvent such as methanol, acetonitrile, or 2-propanol is usually added to the sample solution to prevent their adsorption onto the vessel surface and thus to increase the recovery in SPE. ${ }^{45}$ In this work, the effect of 2-propanol on peak area was studied by extracting PAH solutions with different concentrations of 2-propanol. Results shown in Figure 7 demonstrated that the 2-propanol concentration was a critical parameter. The peak of the relatively high molecular weight benzo[k]fluoranthene increased with 2-propanol concentration, probably because the addition of 2-propanol significantly decreased the viscosity of the sample solution and thus increased the diffusion rate of benzo[k]fluoranthene. Another possible reason is that the addition of 2-propanol decreased the adsorption of benzo[k]fluorantheneonto on the vessel surface. However, the increase of 2-propanol concentration increased the dissolved amount of the $\left[\mathrm{C}_{8} \mathrm{MIM}\right]\left[\mathrm{PF}_{6}\right]$ drop in the sample solution, leading to low analytical response for the low molecular weight PAHs such as fluorene, phenanthrene, and fluoranthene. This was because

(45) M arce, R. M.; Borrull, F. J. Chromatogr., A 2000, 885, 273-290.

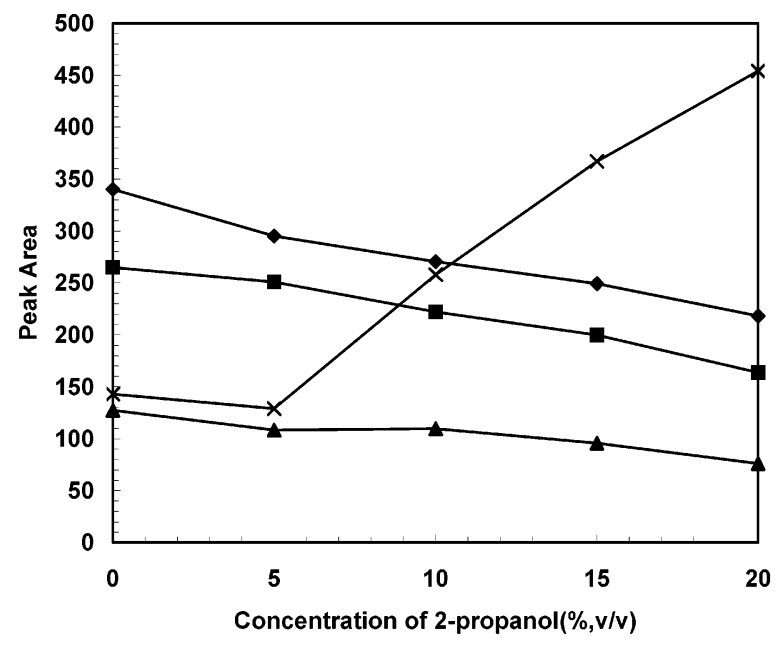

Figure 7. Effect of 2-propanol concentration in aqueous sample on the peak area of PAHs. Sample: $15 \mathrm{~mL}$ of $1 \mu \mathrm{g} / \mathrm{L}$ spiked PAHs in aqueous solution. Extractant: $3 \mu \mathrm{L}$ of $\left[\mathrm{C}_{8} \mathrm{MIM}\left[\mathrm{PF}_{6}\right]\right.$ drop. Extraction time: $30 \mathrm{~min}$. fluorene; $\boldsymbol{\square}$, phenanthrene; $\mathbf{\Delta}$, fluoranthene; $\times$, benzo[k]fluoranthene.

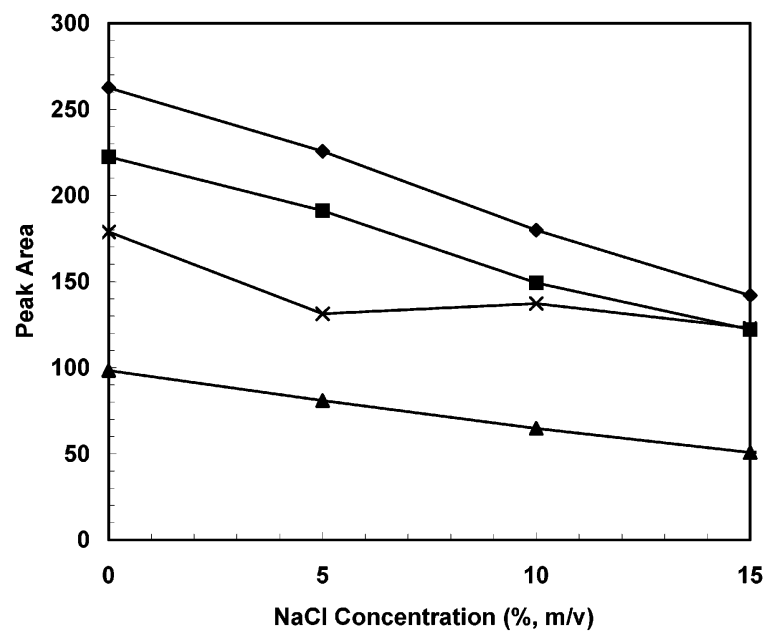

Figure 8. Effect of salt on the peak area of PAHs. Sample: $15 \mathrm{~mL}$ of $1 \mu \mathrm{g} / \mathrm{L}$ spiked PAHs in aqueous solution. Extractant: $3 \mu \mathrm{L}$ of $\left[\mathrm{C}_{8} \mathrm{MIM}\right]\left[\mathrm{PF}_{6}\right]$ drop. Extraction time: $30 \mathrm{~min}$. $\diamond$, fluorene; $\mathbf{\square}$, phenanthrene; $\mathbf{\Delta}$, fluoranthene; $\times$, benzo[k]fluoranthene.

the diffusion rate of low molecular weight PAHs was relatively larger and the adsorption onto the vessel surface was less significant. Thus, their peak areas were mainly dependent on the amount of $\left[\mathrm{C}_{8} \mathrm{M} I \mathrm{M}\right]\left[\mathrm{PF}_{6}\right]$ remaining in the drop that is injected for determination. A concentration of $15 \%$ (v/v) 2-propanol was adopted as a compromise in the following studies.

Salt Effect. In traditional liquid-liquid extraction, the addition of salt often increases the extraction efficiency due to the saltingout effect. Wang et al. ${ }^{30}$ investigated the effect of salt on LPME, and it was reported that the extraction efficiency decreased with the increase in sodium chloride concentration. In this study, the salt effect on LPME of PAHs by IL was investigated by adding different amounts of sodium chloride to the sample and the results are shown in Figure 8. As can be seen, the peak area decreased with the increase of sodium chloride concentration in the studied range of $0-15 \%(w / v)$. Performing extraction in higher concentrations of sodium chloride was difficult as it was not easy to firmly suspend the IL drop. It was observed that the size of the residual 
Table 3. Enrichment Factor, Linearity, and Reproducibility for Extraction of 12 PAHs by the Proposed Direct-Immersion LPME Methoda

\begin{tabular}{lrcc}
\multicolumn{1}{c}{ analyte } & $\begin{array}{c}\text { enrichment } \\
\text { factor }\end{array}$ & $\begin{array}{c}\text { corr } \\
\text { coeff }\left(R^{2}\right)\end{array}$ & $\begin{array}{c}\text { reproducibility } \\
(\mathrm{RSD}, \% \mathrm{n}=5)\end{array}$ \\
naphthalene & 166 & 0.9169 & 9.9 \\
acenaphthylene & 95 & 0.9670 & 12 \\
acenaphthene & 90 & 0.9790 & 11 \\
fluorene & 97 & 0.9976 & 11 \\
phenanthrene & 131 & 0.9957 & 12 \\
anthracene & 105 & 0.9974 & 11 \\
fluoranthene & 106 & 0.9906 & 9.8 \\
pyrene & 109 & 0.9933 & 7.8 \\
benzo[b]fluoranthene & 61 & 0.9976 & 7.8 \\
benzo[k]fluoranthene & 47 & 0.9690 & 9.8 \\
benzo[a]pyrene & 66 & 0.9702 & 3.1 \\
indenol[1,2,3-cd]pyrene & 42 & 0.9846 & 2.8
\end{tabular}

a Conditions: extractant, $3 \mu \mathrm{L}$ of [ $\mathrm{C}_{8} \mathrm{M}$ im] $\left[\mathrm{PF}_{6}\right]$; sample, $15 \mathrm{~mL}$ of PAHs spiked in $15 \%(v / v)$ 2-propanol solution; extraction time, $30 \mathrm{~min}$.

IL droplet after the selected time of extraction was unchanged when different concentrations of sodium chloride were added to the sample solutions. On the other hand, it was reported that the addition of salts in the aqueous phase did not increase the water content in the IL phase. ${ }^{39}$ Thus, the decrease of peak area with the increase of sodium chloride concentration did not result from the dissolving of the IL drop in sample solution. The reason for the decrease of peak area is not clear. Probably it is because the diffusion rate of the PAH molecules, from the bulk sample solution to the IL drop, decreased with the increase of viscosity of bulk sample solution resulting from the increasing of sodium chloride concentration.

Method E valuation. To evaluate the proposed IL-based directimmersion LPME method, some parameters such as linearity, reproducibility, and enrichment factor for the EPA priority PAHs were determined under the above optimized conditions. Linearity was investigated over a concentration range of $0.5-5 \mu \mathrm{g} / \mathrm{L}$ for benzo[k]fluoranthene, benzo[a]pyrene, and indenol[1,2,3-cd]pyrene and $0.5-10 \mu \mathrm{g} / \mathrm{L}$ for the other PAHs. The reproducibility was determined by five repeated extraction of a $5 \mu \mathrm{g} / \mathrm{L}$ spiked water sample. Results shown in Table 3 indicate that, for all the studied PAHs, good linearity with correlation coefficients ranging from 0.9169 to 0.9976 was obtained. The relative standard deviations (RSD, $\mathrm{n}=5$ ) were between 2.8 and $12 \%$ The enrichment factors, which decreased with the PAHs' molecular weights due to decrease of the molecule diffusion rate, were in the range of 42-166 with an enrichment time of $30 \mathrm{~min}$. According to Figure 4, it is obvious that a larger enrichment factor can be obtained if the enrichment time increased to $60 \mathrm{~min}$.

\section{CONCLUSION}

This study demonstrated that the IL $\left[\mathrm{C}_{8} \mathrm{MIM}\right]\left[\mathrm{PF}_{6}\right]$ is an excellent extractant for LPME of PAHs. The unique property of nonvolatility and adequate viscosity allows this IL to be conveniently adopted as extractant in direct-immersion and headspace LPM E. Compared to 1-octanol, [ $\left.\mathrm{C}_{8} \mathrm{M} I \mathrm{M}\right]\left[\mathrm{PF}_{6}\right]$ provides higher extraction efficiency, longer possible extraction time, and much larger drop volume, and thus higher enrichment factor. While a larger enrichment factor was obtained by direct-immersion LPM E for most of the studied compounds, the enrichment factor obtained by headspace LPME of naphthalene is almost 3-fold that by directimmersion LPME, which indicates that headspace LPME is superior to direct-immersion LPME when volatile analytes are extracted.

Although IL are relatively expensive, the proposed IL-based LPME procedure is an inexpensive and one-step microextraction technique as only $3 \mu \mathrm{L}$ of IL was used for each determination. Since IL can be easily synthesized in the laboratory from relatively inexpensive materials and tuned by combination of different anions and cations for task-specific extraction of analytes in various solvent mediums, the method proposed in this paper will have a broad potential in sample preparation, although much more detailed studies regarding both the theoretical and practical aspects should be conducted. It should especially be emphasized that the nonvolatile property of IL makes it potentially useful for headspace LPME of volatile compounds, and this warrants further investigation.

\section{ACKNOWLEDGMENT}

This work was jointly supported by the National Natural Science Foundation of China (20177026, 20137010) and the Chinese Academy of Sciences (KZCX2-414). We thank Prof. Jan Åke Jönsson (Lund University, Sweden) for review of the manuscript.

Received for review May 13, 2003. Accepted August 3, 2003.

AC034506M 